\title{
Lakon Karna Tandhing: Konsep Pergantian Musim dalam Pemujaan Syiwa
}

\author{
Aris Wahyudi \\ Jurusan Pedalangan, Fakultas Seni Pertunjukan Institut Seni Indonesia Yogyakarta \\ Email: ariswayang@yahoo.com
}

\begin{abstract}
Arjuna, Indra's son stands at his war car. General uniform was used making heroic, his left hand hold a bow, and right hand to balance arrow; in the other side Kurawa's army, Prabu Karna, the Surya's son, the commander to play his bow too. When bang of war drum to fill the sky, the both army toward central of Kuruksetra field. The million arrows flaying in the sky like cloudy that closed the sun, and after their hundreds army to yell out dating, afterward the Kuruksetra field flood blood. Suddenly Karna's arrow kicks Arjuna's head. At once surprised who show it. Deities yell congratulation praying. Some minutes the war stop. Arjuna's crown destroyed. Narada descends from the sky give crown to Arjuna that it is exactly with Karna's have. The both hero collide again. Now, Arjuna likes Karna. Arjuna.s angry make increasingly. He get Pasopati arrow. Arjuna lift his bow. Another one who is look when Arjuna frees his arrow, suddenly Karna's head cut off. Kurawa's Hero, Surya's son was dead. This story, in the wayang world it was called Lakon Karno Tandhing. There were can to get some problems. When Arjuna's crown destroyed, Narada prepare a crown to Arjuna. I assume that deity knew that would happen. The question is "Why the crown was prepared similarly Karna have, so it is called Karna Tandhing? I am sure that the composer had a meaning of it. Mythology-ritual analysis shows that this happen is continuity of deity level. All of the hero experiences always involve deity activities. Javanese philosopher composed this story to explain cosmic system that uses symbol systems Lakon Karna Tandhing.

Keywords: Prabu Karna; Arjuna; pasopati; death; Karna Tandhing, cosmic system
\end{abstract}

\begin{abstract}
Abstrak
Arjuna, putra Indra berdiri megah di atas kereta perangnya. Pakaian kebesaran seorang senapati semakin menambah keperkasaannya. Kedua tangannya mengayun gendewa lengkap dengan busurnya. Di pihak lain, Prabu Karna, putra Surya melakukan hal yang sama saat memimpin pasukan Kurawa. Begitu genderang perang bertalu-talu memenuhi angkasa, kedua pihak berhambur ke medan Kuruksetra, saling menyerbu. Ribuan pasukan saling bertempur dan tidak sedikit yang gugur. Tiba-tiba anak panah Karna menghantam kepala Arjuna hingga mahkotanya hancur. Semua yang menyaksikan sangat terkejut, termasuk pula para dewa dewi di angkasa. Narada segera turun ke dunia, memberikan mahkota yang mirip dengan yang dikenakan Karna yang membuat Arjuna mirip dengan Karna. Kedua perwira tersebut kembali bertempur, seakan-akan Karna melawan Karna. Arjuna melepaskan panah pasopati dan tepat memenggal leher Karna. Karna gugur dengan kepala terlempar dan tubuhnya bersandar di kereta perangnya. Kisah ini dalam tradisi pedalangan disebut lakon Karna Tandhing. Dari persoalan tersebut, pertanyaannya adalah: mengapa
\end{abstract}


mahkota yang diberikan Narada tersebut mirip dengan milik Karna? Melalui analisis mitologi-ritual diperoleh pemahaman bahwa peristiwa tersebut merupakan kontinuitas dari peristiwa di tataran mite. Semua peristiwa yang dialami para tokoh epic selalu melibatkan campur tangan tokoh mite. Lakon Karna Tandhing merupakan pengejawantahan peristiwa kosmis yang menjelaskan perpindahan musim kemarau (Karna sebagai putra Surya) berganti dengan musin penghujan (Arjuna sebagai putra Indra). Kesemuanya diatur oleh Syiwa sebagai mahakala yang disimbolkan melalui Arjuna bermahkotakan "Karna".

Kata kunci: Prabu Karna; Arjuna; pasopati; gugur; Karna Tandhing; perubahan musim

\section{Pendahuluan}

Baratayuda, perang besar antara Pandawa dan Kurawa telah mengakibatkan gugurnya empat Senapati Agung Kurawa yang pada dasarnya adalah orang-orang dekat Pandawa. Keempatnya adalah Resi Bisma, Resi Durna (Drona), Prabu Karna, dan Prabu Salya. Resi Bisma adalah kakek dan sekaligus pengasuh Pandawa di masa kecil, gugur di tangan Dewi Srikandi yang dibantu Arjuna dalam Lakon Bisma Gugur. Resi Durna adalah guru Pandawa yang telah mendidiknya sehingga menjadi ksatria unggul (satria pinunjul) gugur di tangan Trustajumna dalam Lakon Durna Gugur. Prabu Karna adalah kakak sekandung Pandawa yang sama-sama dilahirkan oleh Dewi Kunthi gugur di tangan Arjuna dalam Lakon Karna Tanding. Prabu Salya adalah paman Pandawa yang sangat menyayangi dan mengasihinya gugur di tangan Prabu Puntadéwa dalam Lakon Salya Gugur.

Dari keempat lakon tersebut di atas, Lakon Karna Tandhing memiliki daya tarik tersendiri, yakni masalah yang ditampilkan dan penggunaan judulnya, yaitu Karna Tandhing. Pertempuran Karna melawan Arjuna merupakan peristiwa yang paling dilematis, bukan saja bagi Pandawa tetapi yang lebih hebat lagi adalah Dewi Kunthi. Menjelang perang besar itu pecah, Prabu Karna menemui Dewi Kunthi untuk yang pertama dan sekaligus terakhir kalinya -dikisahkan dalam Lakon Kresna Duta-. Meskipun dalam pertemuan tersebut Dewi Kunti dengan berbagai upaya memohon dengan sangat agar Prabu Karna bersatu dengan Pandawa, tetapi Prabu Karna dengan tegas menyatakan tetap berada di pihak Kurawa, sebagai lawan Pandawa, sebagai wujud dari kesetiaan atas sumpahnya kepada Prabu Duryudana. Beberapa dalang mengisahkan bahwa ketetapan Prabu Karna tersebut sebagai wujud rasa sayangnya kepada Pandawa dan tanggung jawabnya sebagai saudara tua yang harus menyelamatkan dan mensejahterakan adik-adiknya. Menurut Prabu Karna, hanya dengan pecahnya Baratayudalah Pandawa dapat hidup tenang, dan Baratayuda terjadi, maka Prabu Karna harus berada di pihak Kurawa sebagai Benteng Kurawa. Agar Pandawa mencapai kejayaan, maka dalam Baratayuda nanti, ia harus melawan Arjuna. Meski demikian bukan berarti Karna akan mengalah, tetapi Arjuna harus mampu mengalahkan dia; apabila tidak, maka Arjunalah yang akan dibunuh Karna dalam perang (lihat Ki Narto Sabdo dalam Lakon Kresna Duta; Ki Mudjoko Djoko Rahardjo dalam Lakon Krena Duta). Dikisahkan dalam Lakon Karna Tandhing bahwa meskipun Prabu Karna rela mati di tangan Arjuna, tetapi bukan berarti dia akan mengalah begitu saja. Dia akan tetap berdiri sebagai ksatria dan senapati yang bertanggung jawab atas tugasnya (periksa Mulyono, 1992: 54).

Yang menarik lagi adalah, dari keempat lakon tersebut hanya Lakon Karna Tandhing yang tidak menggunakan istilah gugur sebagai judul. Sepintas, dipilihnya Karna Tandhing sebagai judul tampaknya didasarkan pada peristiwa setelah Arjuna dihancurkan mahkotanya. Begitu mahkota Arjuna hancur oleh panah Prabu Karna, Narada segera turun ke madyapada membawa sebuah mahkota untuk mengganti mahkota Arjuna yang hancur. Mahkota tersebut wujudnya persis dengan kepunyaan Prabu Karna. Oleh karena wajah Arjuna mirip dengan Prabu Karna dan pada saat itu memakai mahkota yang sama pula sehingga keduanya persis dalam segala hal; ketampanan, kepandaian memanah, maupun kelincahannya. Pada saat itu seolah-olah dua 
Prabu Karna yang sedang bertanding, sehingga disebut Karna Tanding. Artinya bahwa peristiwa hancurnya mahkota Arjuna merupakan dasar atas penggunaan nama Karna Tanding untuk lakon tersebut. Sebagaimana dikisahkan bahwa; begitu mahkota Arjuna hancur, serta merta Batara Narada turun ke marcapada dengan membawa mahkota pengganti dari mahkota Arjuna yang hancur. Dari sini dapat diasumsikan bahwa Dewa telah menyiapkan mahkota tersebut, artinya dewa telah mengetahui apa yang akan terjadi. Dan seandainya benar, yang menjadi pertanyaan adalah: "Mengapa mahkota yang disiapkan bentuknya sama dengan kepunyaan Prabu Karna?

Membahas persoalan wayang tidak dapat lepas dari kapasitasnya sebagai representasi jagad mitis masyarakat Jawa. Penelitian menunjukkan bahwa wayang sebagai lapis mitis ke-dua merupakan "realitas sosial" yang di dalamnya mengandung kaidah dan norma tentang pranata sosial dan ritual. Khususnya berkenaan dengan pranata ritual, dipahami dalam jagad wayang bahwa masing-masing tokoh manusia (epik) merupakan inkarnasi dari tokoh dewa (mite) (Wahyudi, 2012: 26). Di sini terdapat pemahaman bahwa peristiwa yang dialami oleh tokoh titah selalu melibatkan campur tangan dari tokoh-tokoh dewa. Campur tangan tersebut ditunjukkan melalui sistem simbol yang berupa inkarnasi, kepemilikan atas sesuatu, karakter, ciri-ciri fisik, dan keturunan (Hiltebeitel, 1990: 35-37). Berdasarkan pandangan tersebut maka dalam penelitian ini wayang dihargai sebagai sebuah "dunia" tersendiri, sebuah cerita yang sangat panjang yang telah membangun sebuah "realitas" kehidupannya. Dengan demikian untuk memahami Lakon Karna Tandhing ini tidak dapat mengabaikan hubungan dan kesinambungannya dalam mata rantai lakon-lakon yang berhubungan dengan Karna dan Arjuna (intertekstualitas) (Wiryamartana, 1990: 10-11).

Aspek Mite Karna dan Arjuna dianalisis melalui konsep asma kinarya japa (setiap nama selalu memiliki makna/sebagai mantra), karena fenomena nama, bagi masyarakat Jawa memiliki arti penting (Wahyudi, 2009: 73). Asma di sini dipandang sebagai "sebutan" (pengucapan). Asma dapat diidentikkan dengan penanda sebagai wadah dari sebuah konsep; sedangkan konsepnya adalah japa. Dengan demikian konsep asma kinarya japa seperti halnya terminologi, yakni melacak pengertian nama, digunakan untuk melacak dan menjelaskan makna serta sumber konsep-konsep lakon wayang berdasarkan kontek intertekstualnya; yakni penggunaan konsep asma kinarya japa dalam melacak identifikasi Karna dan Arjuna dalam kaitannya dengan Karna Tanding dalam Baratayuda. Proses penafsiran mengenai aspekaspek yang menjadi dasar atas semua permasalahan dalam Lakon Karna Tandhing direlasikan dengan atau mengacu pada jagad pikir mitis orang Jawa.

\section{Lakon karna Tandhing sebagai Transformasi Pergantian Musim}

Dipahami dalam tradisi wayang bahwa Karna dan Arjuna sama-sama putra Kunti, tetapi dari ayah yang berbeda. Karna adalah putra Dewa Surya sedangkan Arjuna adalah putra Dewa Indra. Meskipun demikian, apabila ditarik ke belakang, sebenarnya sarana yang digunakan dalam proses kelahiran keduanya adalah sama, yakni lantaran ajian Kuntaherdaya pemberian Resi Druwasa, penasehat spiritual Kerajaan Mandura pada saat Dewi Kunti masih remaja.

Prabu Karna lahir di kerajaan Mandura ketika Dewi Kunti masih belum menikah. Dikisahkan bahwa Dewi Kunti membaca mantra Kuntaherdaya yang kemudian Dewa Surya turun ke dunia menemui Dewi Kunti, di situlah terjadi percintaan yang kemudian melahirkan Prabu Karna. Oleh karena itu, bayi tersebut diberi nama Suryatmaja, yang artinya putra Dewa Surya, penguasa Matahari. Karena status Dewi Kunti yang saat itu belum bersuami, tentunya kehamilan Dewi Kunti yang tanpa suami ini merupakan aib bagi Negara. Agar nama baik Negara Mandura tidak tercoreng, maka peristiwa tersebut harus dirahasiakan. Cara yang ditempuh adalah dengan menghanyutkan bayi tersebut di sungai Yamuna, yang akhirnya ditemukan Adirata, kusir Negara Ngastina. Dalam tradisi wayang Ngayogyakarta, bayi tersebut ditemukan Prabu Radeya, raja Negara Merthaperlaya. Meskipun Prabu Radeya seorang raja (kecil), tetapi ia adalah kusir negara Ngastina. Dengan demikian kontinuitas Karna dibesarkan oleh kusir Ngastina masih terjaga.

Setelah Karna besar, ketika diselenggarakan pendadaran murid-murid Resi Durna, Karna 
remaja ikut nimbrung untuk memamerkan kepandaiannya. Melihat keahlian Karna remaja dalam memainkan senjata dan kesaktian, kemudian Prabu Duryudana merekrutnya menjadi sekutu dan menobatkan Prabu Karna sebagai Adipati -raja bawahan Ngastina- di kerajaan Ngawangga (bandingkan dengan Lakon Alap-alapan Surtikanti. Ki Hadi Sugito). Prabu Karna mendapatkan Negara Ngawangga, dalam tradisi wayang Ngayogyakarta dikisahkan atas hasil jerih payahnya sendiri, yakni mengalahkan raja Ngawangga, Prabu Karnamandra, seorang raksasa sakti. Gelar Prabu Karna adalah mengikuti jejak (nunggak semi) gelar Prabu Karnamandra. Sebelum menjadi raja, Prabu Karna bernama Raden Suryatmaja.

Kisah tentang proses Dewi Kunti hamil Arjuna dalam tradisi wayang tidak diceritakan. $\mathrm{Na}$ mun demikian, ada petunjuk dari Adiparwa yang dapat ditarik benang merahnya mengenai kelahiran Arjuna. Dikisahkan bahwa pada suatu hari Prabu Pandu merasa bersedih karena tidak dapat memberikan keturunan kepada Dewi Kunti dan Dewi Madrim karena telah dikutuk oleh seorang brahmana. Atas ijin Prabu Pandu, Dewi Kunti menggunakan mantra Kuntaherdaya untuk menghadirkan seorang Dewa. Untuk Putra ke-tiga, Dewi Kunti menghadirkan Dewa Indra dan memberinya keturunan. Setelah bayi lahir diberi nama Arjuna, juga disebut Indratanaya yang artinya putra Dewa Indra (Widyatmanta, 1968: 13). Dengan demikian, Arjuna sebagai putra Prabu Pandu, raja Ngastina pada dasarnya hanyalah status belaka. Ayah Arjuna yang sebenarnya adalah Dewa Indra.

Aspek Indra dalam diri Arjuna ditunjukkan dalam Adiparwa sebagai berikut. "Lumampah ta sira marang Bhatāra Wisnu, mājarakên i pañjanma nira manusya. ... Kunang janma nikang pancendriya, yekà sang pañca Pandawa.... ('Berjalanlah ia [Batara Indra] menuju Batara Wisnu, menceritakan penjelmaannya [menjadi] manusia. .... Adapun panca inderanya [Batara Indra] akan menjelma menjadi lima Pandawa') (Widyatmanta, 1968: 12). Teks tersebut jelas menunjukkan bahwa Arjuna merupakan inkarnasi dari salah satu indera Bathara Indra. Dalam tradisi Mahabharata, dipahami bahwa Pandawa adalah Indra yang berwujud (menjelama menjadi) manusia - all "Indras among men”- (Hiltebeitel, 1990 : 200). Dari pernyataan tersebut dapat dipahami bahwa Arjuna bukan saja sebagai putra Dewa Indra, tetapi sekaligus inkarnasi dari Dewa Indra itu sendiri.

Mengikuti pandangan Hiltebeitel (1990) bahwa semua peristiwa yang dialami oleh semua tokoh epic -wayang- selalu melibatkan tokoh dewa, maka pertempuran antara Prabu Karna dan Arjuna tersebut merupakan pertentangan antara Dewa Surya dan Dewa Indra. Meskipun demikian bukan berarti pertentangan yang begitu saja, tetapi terdapat konsep-konsep tertentu di dalamnya; apalagi bila dikaitkan kapasitas wayang sebagai pengetahuan orang Jawa mengenai makrokosmosnya. Artinya bahwa dalam Lakon Karna Tandhing ini mengandung pengetahuan tentang pranata kosmos. Pemahaman demikian, apabila dikaitkan dengan kapasitas Dewa Surya adalah penguasa matahari, yang mengatur peredaran matahari. Dewa Indra adalah penguasa hujan, yang mengatur peredaran hujan. Oleh karena itu pertentangan Karna dan Arjuna dalam Lakon Karna Tandhing dapat diasosiasikan sebagai peredaran musim hujan dan musim kemarau. Kematian Prabu Karna diasosiasikan sebagai berakhirnya musim kemarau dan digantikan musim penghujan. Asosiasi ini dapat dilacak melalui pertentangan Surya dan Indra dalam tataran mite.

Salah satu yang menarik dalam perang Karna melawan Arjuna adalah kemunculan naga Hardawalika. Ketika Prabu Karna sedang siap-siap bertempur menghadapi Arjuna, datang seekor naga yang ingin membantu membunuh Arjuna, tetapi Prabu Karna merasa terhina sehingga menolaknya dengan keras. Ia ingin berhadapan dengan Arjuna sebagai ksatria sejati. Sang naga kemudian meninggalkan Prabu Karna langsung melesat ke angkasa menuju tempat Arjuna dengan mengendarai awan. Atas petunjuk Prabu Kresna, Arjuna siaga dan sang naga berhasil dibunuhnya. Dan pada akhirnya, Prabu Karna pun gugur di tangan Arjuna dengan senjata pasopati, kepalanya terpenggal.

Peristiwa di atas apabila ditarik dalam tataran mite dapat diasosiasikan dengan peristiwa pertempuran antara Indra melawan Vrrtra (Katz, 1989: 32; Hiltebeitel, 1990: 242-243). Vṛtra adalah pelindung 99 sembilan raksasa (Macdonell, 1974: 61), sebagaimana halnya Kurawa adalah inkarnasi 99 raksasa putra Pulasya (Padmosoekoco, 1990: 134). Kematian Prabu Karna merupakan kontinuitas dari kematian Vṛtra yang dipenggal lehernya 
oleh Indra dengan menggunakan vajra (Hiltebeitel, 1990: 263); seperti halnya Prabu Karna yang gugur di tegal Kuruksetra, kepalanya terpenggal oleh Pasopati, senjata Arjuna. Kekalahan Prabu Karna sebagai manifestasi kekuatan matahari di tangan Arjuna sebagai kekuatan hujan merupakan hukum alam. Fenomena demikian dapat dijumpai dalam pepatah "panas setahun dihapus hujan sehari"; artinya bahwa kekuatan matahari yang begitu dahsyat tetap saja kalah dengan kekuatan hujan.

Namun demikian, penelitian lain menafsirkan bahwa Vrrtra adalah seekor naga (Macdonell, 1974: 61; Katz, 1989: 32). Indra mengalahkan Vṛtra untuk membebaskan air. Ketika Indra mengalahkan naga Vṛtra untuk memberikan air kepada manusia. Peristiwa itu dipandang sebagai saat Indra membuat hari menjadi fajar dan kemudian matahari bersinar. Dalam beberapa faham, fajar dikatakan sebagai perayaan atas keberhasilan kerjasama Indra dengan matahari dalam waktu yang panjang setelah berhasil menguasai air. Setelah itu, Indra menempatkan matahari di surga (Macdonell, 1974: 61). Artinya bahwa Vrrtra semula sebagai penguasa air, yang kemudian dikuasai Indra.

Kapasitas Vṛtra sebagai naga menunjukkan kedekatannya dengan peristiwa yang terjadi dalam Karna Tanding tradisi wayang, yakni melalui kehadiran naga Hardawalika. Dikisahkan dalam Lakon Karna Tandhing bahwa setelah tawarannya untuk membantu Prabu Karna ditolak, Naga Hardawalika segera melesat ke angkasa. Ia ingin membunuh Arjuna. Dengan mengendarai awan, Hardawalika melesat menuju tempat Arjuna. Prabu Kresna yang pada saat itu menjadi kusir kereta perang Arjuna, melihat gerak-gerik Hardawalika. Kresna segera memerintahkan Arjuna untuk menyirnakannya. Dalam sekejap, anak panah Kyai Sarotama, senjata Arjuna yang sangat sakti telah memenggal kepala Hardawalika. Naga dalam tradisi Mahabharata dipahami sebagai symbol air, dalam kapasitasnya sebagai sumber kehidupan (Bhattacharji, 1970: 150). Dengan demikian dapat dipahami apabila Vṛtra sebagai naga adalah penguasa air.

Fenomena Vrrtra tersebut juga ditunjukkan dalam fenomena Lakon Karna Tandhing. Pada saat akan membunuh Arjuna, Hardawalika mengendarai awan yang kemudian dapat dibunuh Arjuna; seperti halnya Vṛtra yang menyerang Indra, tetapi gagal dan bahkan dia sendiri yang dibunuh Indra. Indra berhasil merebut air dari Vṛtra dan menjatuhkannya menjadi hujan untuk memberi penghidupan kepada makhluk di bumi (Macdonell, 1974: 61). Hardawalika yang pada saat itu berselimut awan, ketika panah Arjuna menerjangnya, awan yang menyelimutinya menjadi hancur dan jatuh ke bumi (Tegal Kuruksetra). Identifikasi Prabu Kresna sebagai pembantu Arjuna akan menjadi jelas dengan melihat kapasitas mitologi keduanya. Prabu Kresna pada peristiwa Karna Tanding merupakan perwujudan Wisnu Wisnu mangéjawantah- yang sedang membantu Arjuna sebagai manifestasi Indra.

Kapasitas Arjuna sebagai manifestasi Indra ditunjukkan melalui nama atau gelar Arjuna. Arjuna memiliki gen Sang Nara yang artinya, Arjuna sebagai manusia yang sekaligus dewa atau manungsa asipat dewa yang merupakan pasangan Kresna sebagai Nara - Narayana (Katz, 1989: 215). Dalam tradisi wayang pun, perpasangan Arjuna Kresna demikian masih sangat lekat; diibaratkan cincin dan permatanya; kereta dan saisnya; seperti halnya pasangan Indra dan Wisnu; yang mana Wisnu adalah pasangan Indra (periksa juga Macdonall, 1974: 39). Oleh karena itu, dalam Baratayuda pun Prabu Kresna berdiri sebagai sais Arjuna. Bukan saja pada event Baratayuda, bahkan dalam peristiwa-peristiwa yang lain pun menunjukkan posisi Prabu Kresna sebagai manifestasi Wisnu berdiri sebagai pembantu Pandawa sebagai manifestasi Indra. Kapasitas Wisnu yang demikian pula sehingga Prabu Kresna pun didudukkan sebagai duta Pandawa dalam meminta kembali haknya atas Negara Ngastina. Fenomena demikian juga ditunjukkan dalam beberapa lakon wayang.

Berdasarkan keterkaitan antara Prabu Karna, Hardawalika, Arjuna, dan Prabu Kresna dalam Lakon Karna Tandhing bahwa Hardawalika memiliki keterkaitan antara matahari dan air, yang dalam hal ini hujan. Hal ini dapat dilacak melalui simbol naga. Naga dapat diasosiasikan sebagai penguasa air (Kuiper, 1979: 97; Bhattacharji, 1970: 39). Baruna dalam kapasitasnya sebagai penguasa air dapat diasosiasikan dengan naga sebagaimana yang ditunjukkan dalam Lakon Antasena Lair yang menyatukan Baruna dan Antaboga dalam mendidik Antasena (Wahyudi, 2012: 587). Demikian halnya dengan Hardawalika. Sebagai penguasa air, ketika akan membunuh Arjuna, ia 
menggunakan mendung untuk melindungi dirinya. Namun usaha demikian diketahui oleh Prabu Kresna yang kemudian mengisyaratkan kepada Arjuna bahwa ada musuh yang mengintai. Dengan sigap panah Arjuna melesat ke arah Hardawalika dan tepat mengenai leher hingga kepalanya putus. Meskipun dalam wayang tidak diceritakan tentang awan yang menyelimuti Hardawalika, namun dapat diasumsikan bahwa awan tersebut hancur berhamburan dan jatuh ke bumi. Fenomena ini apabila dihubungkan dengan peristiwa kematian Vrrtra oleh senjata Indra, maka dapat diasosiasikan sebagai proses terjadinya hujan.

Apabila proses terjadinya hujan tersebut dikaitkan dengan pertentangan Prabu Karna dan Arjuna dapat dikatakan sebagai personifikasi pertentangan antara panas dan hujan. Prabu Karna sebagai manifestasi Surya dapat diasosiasikan sebagai panas. Sebagaimana fenomena yang dijumpai dalam realitas bahwa matahari memberikan panas kepada bumi. Apabila matahari bersinar sehari penuh mampu membuat kering barang-barang yang basah. Semakin lama matahari bersinar akan semakin membuat panas dan kekeringan di bumi. Dalam kaitannya dengan kapasitas Prabu Karna sebagai matahari, semakin berjaya Prabu Karna atau semakin lama Prabu Karna berkiprah dalam lakon Baratayuda, dapat diasosiasikan bahwa selama itu pula matahari menyinari bumi. Peredaran siklus di mana matahari bersinar lama dalam masyarakat Jawa disebut musim kemarau. Apabila kemarau berlangsung terlalu lama maka akan mengakibatkan bencana kekeringan. Oleh karena itu untuk mencapai keseimbangan, musim kemarau atau musim kering harus berganti musim hujan atau musim basah. Pergantian musim di sini merupakan tugas Wisnu sebagai dewa pemelihara alam. Oleh karena itu Prabu Kresna sebagai manifestasi Wisnu mengendalikan Arjuna sebagai manifestasi Indra, penguasa hujan untuk membasahi bumi dengan hujannya.

- Thus reinforced, Indra attacked Vrtra again, after gods and seers had made a contract with Vrtra, to the effect that he sould not be killed with "dry or wet, stone or wood", etc. But Visnu entered foam and Indra smote Vrtra with it ("dry and wet" thunderbolts are recognized among magic arms). (Hopkins, 1986: 131)
Berdasarkan kutipan di atas, kapasitas Arjuna dan Prabu Kresna melawan Prabu Karna sebagai keterulangan tentang pertempuran Vrrtra melawan Indra yang dibantu Wisnu merupakan persoalan kering (musim kemarau) dan basah (musim hujan).

Fenomena siklus musim ini semakin jelas dengan kehadiran Prabu Salya. Dalam tradisi epik, Salya merupakan simbol bumi (Hiltebeitel, 1990: 266). Relasi Prabu Karna sebagai senapati dan Prabu Salya sebagai sais merupakan identifikasi relasi matahari dan bumi. Dalam peredaran musim, yang menjadi pengendali adalah bumi. Bumilah yang bergerak mengelilingi matahari dan sekaligus berotasi pada porosnya. Rotasi inilah yang menciptakan siang dan malam; sedangkan peredaran bumi pada orbitnya yang menciptakan musim selama satu tahun. Peredaran inilah yang disimbolkan kapasitas Prabu Salya (bumi) sebagai sais yang menjalankan (beredar dan berotasi mengelilingi) kereta Prabu Karna (matahari). Prabu Karna yang berdiri tegak sebagai senapati merupakan identifikasi matahari yang berada (konstan) pada posisinya.

Bumi sudah menghendaki datangnya musim penghujan. Artinya bahwa tindakan Prabu Salya menghentakkan kereta ketika Prabu Karna memanah Arjuna merupakan cara bumi menyelamatkan penguasa hujan dan melemahkan kekuatan penguasa kemarau (bandingkan dengan Hiltebeitel, 1990: 255). Di sisi lain, Salya sebagai Bumi tentu berpihak pada Prabu Kresna sebagai manifestasi Wisnu, suami pertiwi. Dengan demikian keputusan Prabu Karna memilih Prabu Salya sebagai sais kereta perangnya merupakan hukum alam yang mengatur tentang peredaran musim. Kematian Prabu Karna di tangan Arjuna merupakan representasi kemenangan Indra sebagai penguasa hujan atas Vrrtra sebagai penguasa kemarau dalam arti berakhirnya musim kemarau dan beralih ke musim penghujan. Kemampuan naga untuk "mlungsungi" (membuat kembali muda) diasosiasikan sebagai spirit dari siklus (Bhattacharji, 1970: 176). Artinya bahwa pergantian musim tersebut merupakan siklus yang akan terulangulang terus.

Istilah hardawalika berasal dari dua kemungkinan kata bentukan. Pertama, berasal dari kata harda dan walika. Kata harda dalam bahasa Jawa memiliki pengertian "kehendak yang berkobar- 
kobar". Kata walika yang berdiri sendiri tidak dijumpai dalam bahasa Jawa. Istilah dalam bahasa Jawa Kuna yang paling mendekati walika adalah walik yang artinya balik, kembali, ulang; atau dari kata wali yang artinya "sebaliknya", atau "walaupun demikian" (Mardiwarsito, 1990: 656-657). Pengertian kata harda di atas secara sintakmatik dengan pengertian walika dalam hubungannya dengan iklim hujan dan kemarau tampak tidak memiliki relasi; atau dengan kata lain tidak bermakna. Kedua, berasal dari kata ardha yang artinya setengah "setengah"; "agak"; "sedikitpun" (Mardiwarsito, 1990: 73). Pengertian ini masih memiliki relasi sintagmatik dengan kata walika, yakni menjadi "setengah sebaliknya"; yang dapat diambil pengertian bahwa setengan bagian merupakan kebalikan dari setengah bagian yang lain. Dengan pengertian ini dapat ditarik benang merah bahwa setelah kematian Hardawalika di sini merupakan pertanda bahwa musim kemarau telah berlangsung selama separuh dari sebuah musim, oleh karena itu akan dibalik menjadi musim hujan.

Kapasitas Prabu Karna dan Arjuna sebagai transformasi musim kemarau dan penghujan diindikasikan melalui pusaka mereka. Prabu Karna memiliki pusaka Kala Dité, sedangkan pusaka Arjuna adalah Kala Nadhah. Dité merupakan nama lain dari Matahari; dan kala artinya waktu. Dengan demikian Kala Dité dapat dimaknai sebagai waktu matahari atau musim kemarau. Istilah nadhah dalam bahasa Jawa berasal dari kata dasar tadhah yang mendapat awalan hanuswara "an". Antadhah, konsonan $t$ luluh menjadi kata kerja aktif nadhah artinya menampung. Berdasarkan arti kata nadhah tersebut dapat diasosiasikan bahwa nadhah ini memiliki relasi sintagmatik dengan hujan, sebagaimana ditunjukkan dalam kebiasaan tradisi Jawa bahwa istilah nadhah banyak dikaitkan dengan air atau benda cair, seperti dalam istilah nadhahi banyu ('menangkap air yang jatuh dari atas dengan menggunakan alat'), atau laladan tadhah udan ('daerah tadah hujan atau daerah yang sumber air utamanya adalah air hujan'). Dengan demikian kematian Karna di tangan Arjuna merupakan kematian waktu matahari (kemarau) oleh waktu air (hujan); dan peristiwa ini selalu berlulang sebagai siklus yang diidentifikasikan melalui Naga Hardawalika.

\section{Lakon Karna Tandhing: Yoga Arjuna dalam Pemujaan Syiwa}

Keseluruhan peristiwa yang terjadi dalam Lakon Karna Tandhing di atas, selain sebagai pengetahuan tentang pergantian musim kemarau ke musim hujan, pada aspek lain merupakan identifikasi proses ritual, sebagai perang ritual (periksa Hiltebeitel, 1990: 244). Pemujaan dalam tradisi Hindu India terdiri dari tiga "mashab" besar, yaitu (1) Hindu Wedik yang orientasi pemujaannya kepada Dewa Brahma; (2) Hindu Tantrik yang orientasi pemujaannya kepada Dewa Syiwa; dan (3) pemujaan Dewa Wisnu (Bhattacharji, 1970: 14-16). Masing-masing mashab memiliki tatacara ritual yang berbeda antara satu dengan yang lainnya. Berdasarkan fakta yang ditampilkan dalam lakon Karna Tandhing tampak bahwa Arjuna diposisikan sebagai yogin yang sedang melakukan yoga pemujaan Syiwa.

Sebagaimana dikisahkan bahwa Prabu Karna memang benar-benar ahli dalam memanah. Meskipun Prabu Salya telah menghentakkan kuda keretanya agar posisi anak panah Prabu Karna melenceng; dan demikian juga Prabu Kresna menghentakkan kereta hingga rodanya amblas ke bumi, namun tetap saja panah Prabu Karna mengenai mahkota Arjuna hingga hancur. Saat itu juga Bathara Narada turun ke dunia membawa mahkota untuk menggantikan mahkota Arjuna yang hancur. Mahkota tersebut persis dengan mahkota Prabu Karna sehingga cerita ini disebut Lakon Karna Tandhing.

Peristiwa tersebut apabila dicermati, ternyata bukan sesuatu yang terjadi secara kebetulan. Hancurnya mahkota Arjuna merupakan peristiwa yang harus terjadi untuk digantikan dengan mahkotanya yang baru, yang dibawa dari kayangan. Artinya bahwa para dewa sudah mengetahui apa yang akan terjadi dan mempersiapkan mahkota Arjuna yang mirip dengan milik Prabu Karna. Makna yang tersimpan dalam peristiwa ini dapat dilacak melalui berbagai identifikasi yang ditampilkannya.

Fakta dalam tradisi wayang menunjukkan bahwa tokoh yang memiliki mahkota yang sama persis dengan Prabu Karna hanyalah Bathara Guru, yakni Bathara Guru wanda Karna. Dalam tradisi wayang, tokoh Bathara Guru memiliki dua 
ikonografi, yaitu Bathara Guru wanda reca dan Bathara Guru wanda Karna. Berpijak dari fakta ini, dan fenomena mitis dalam jagad wayang bahwa semua peristiwa yang terjadi dalam Baratayuda melibatkan campur tangan tokoh mite (bandingkan dengan Katz, 1989: 242), serta berdasarkan identifikasi wanda Bathara Guru dan mahkota yang digunakan Arjuna maka dapat diasosiasikan bahwa Arjuna dalam peristiwa ini, selain sebagai manifestasi Indra sekaligus juga manifestasi Syiwa. Fenomena demikian sangat mungkin terjadi dalam jagad wayang sebagaimana yang terjadi dalam Lakon Begawan Mintaraga atau Arjunawiwaha. Ketika berhadapan dengan Resi Padya, kapasitas Arjuna adalah sebagai manifestasi Bathara Indra (bertapa di gunung Indrakila atau Indrakaelasa); dan ketika berhadapan dengan Keratarupa (Penjelmaan Bathara Guru/Syiwa), Arjuna bediri sebagai manifestasi Syiwa. Hal ini ditunjukkan dengan menyatunya anak panah Arjuna dengan Keratarupa; dan kemudian menerima panah pasupati. Istilah pasupati atau pashupati artinya penguasa binatang, "lord of animals) (Katz, 1989: 253). Yang dimaksud binatang di sini adalah binatang korban atau pasubanda. Sebagaimana dijelaskan Surasmi bahwa di dalam Tantrayana, pasubanda merupakan aspek penting dalam ritual pemujaannya. Dengan demikian dalam melacaknya adalah menjelaskan fenomenafenomena dalam lakon yang mengidentifikasikan sebagai yadnya pasubanda; dan jelas ditunjukkan bahwa yang menjadi yadnya adalah dua tokoh, yakni Hardawalika dan Prabu Karna.

Kematian Naga Hardawalika dalam Lakon Karna Tandhing selain identifikasi jatuhnya hujan, tetapi di sisi lain sekaligus menegaskan indikasi Syiwaistik. Sebelum mahkota Arjuna hancur dan digantikan mahkota Syiwa, terlebih dahulu ia membunuh naga Hardawalika yang pada saat itu sedang berselimut awan. Apabila awan merupakan asosiasi dari air, maka di sini Hardawalika menguasai air. Dengan demikian kapasitas Hardawalika sebagai naga merupakan asosiasi dari "spirit of water", yang merupakan identifikasi "sakti" Syiwa (Bhattacharji, 1970: 12). Dalam berbagai relasi interteks tersebut, awan yang menyelimuti atau melingkari Hardawalika memiliki relasi paradigmatik dengan cakrabyuha; sedangkan cakrabyuha merupakan identifikasi
Durga, dan Durga adalah "sakti" Syiwa. Artinya bahwa di sisi lain, Arjuna membunuh naga Hardawalika merupakan asosiasi penyatuan Siwa dengan Śakti-nya. Dengan demikian rangkaian peristiwa yang dialami Arjuna dalam Lakon Karna Tandhing tersebut merupakan relasi-relasi dari air, siklus (cakrabyuha), dan sakti; yang merupakan aspek penting dalam pemujaan Syiwa.

Kaitannya dengan Syiwa sebagai pasupati, keberadaan pasubanda dalam pemujaan Syiwa merupakan sebuah keharusan. Dalam Lakon Karna Tandhing terdapat tiga pasubanda yang dapat diindikasikan sebagai yadnya Arjuna, yaitu Naga Hardawalika, dirinya sendiri, dan Prabu Karna. Hardawalika sebagai naga merupakan korban ular. Kemudian Arjuna sendiri juga menjadi "korban" yang diidentifikasikan melalui mahkota yang hancur oleh senjata Prabu Karna. Dengan kedua yadnya tersebut Arjuna berhasil mencapai penyatuan dengan Syiwa sebagai isthadewata-nya; dan Arjuna berdiri sebagai Syiwa itu sendiri, sebagai pasupati yang diindikasikan melalui panah, yang kemudian digunakan untuk membunuh Prabu Karna dengan lehernya ditebas oleh panah pasupati milik Arjuna yang pada saat itu sudah berbusana kebesaran Syiwa (Bathara Guru wanda Karna). Di sinilah terjadinya peyatuan Arjuna sebagai yogin dan Syiwa sebagai isthadewata-nya. Dengan demikian jelas menunjukkan bahwa Prabu Karna adalah pasubanda yang menjadi yadnya Arjuna sebagai yogin dalam rangka menyatukan dirinya dengan Syiwapasupati.

Kapasitas Arjuna sebagai pemuja Syiwa demikian juga ditunjukkan dalam Lakon Arjunawiwaha. Disebutkan bahwa penobatan Arjuna sebagai raja di kahyangan merupakan penyatuan Arjuna dengan Hakekat Syiwa (Wiryamartana, 1990: 372). Hal ini ditunjukkan melalui kemiripan pola yadnya antara Lakon Arjunawiwaha atau Begawan Ciptahening dengan Karna Tandhing yakni binatang dan raksasa. Yadnya pertama dalam kedua lakon tersebut adalah binatang. Mamangmuka adalah yadnya Arjuna dalam Lakon Arjunawiwaha; dan Hardawalika adalah yadnya Arjuna dalam Lakon Karna Tandhing. Keberhasilan Arjuna membunuh Naga Hardawalika sebagai spirit of water atau air kehidupan, atau amerta seperti halnya dalam Lakon Dewa Ruci ketika Bima membunuh Naga Nabatnawa, yaitu 
keberhasilan Arjuna mengendalikan kundalini sakti sehingga mampu mencapai lompatan spiritual menuju alam kadewatan atau alam niskala (periksa Wahyudi, 2012: 591).

Hancurnya mahkota Arjuna oleh panah Prabu Karna, selama ini dalam jagad pedalangan dipandang sebagai "kekurangan" atas kesaktian Arjuna. Bahkan peristiwa tersebut dipandang sebagai perilaku "curang" Prabu Salya dan Prabu Kresna yang menurunkan citra kepahlawanan Arjuna. Namun demikian apabila dipandang dari kapasitas tataran epik - ritual - mite atas tokoh Prabu Salya, Arjuna dan Karna, serta Prabu Kresna menunjukkan fenomena tersebut sudah seharusnya terjadi.

Berdasarkan kapasitas Baratayuda sebagai perang ritual (baca Hiltebeitel, 1990), maka baik Prabu Karna maupun Arjuna sama-sama sebagai seorang yogin. Pada dasarnya Prabu Karna dan Arjuna merupakan tokoh sakti pemuja (yogin) Syiwa. Prabu Karna sebagai daitya (ditya/raksasa) sakti, sedangkan Arjuna sebagai manusia (ksatria) sakti. kesatria yang sakti. Kapasitas Prabu Karna sebagai ditya dapat dilihat dari kapasitasnya sebagai putra Surya dan inkarnasi Prabu Karna Mandra (dalam tradisi wayang Ngayogyakarta).

Tokoh Prabu Karna Mandra, raja Negara Ngawangga adalah raksasa sakti yang ingin mempersuntung Dewi Surtikanthi. Usaha tersebut gagal karena dia gugur di tangan Raden Suryatmaja, putra Prabu Radeya. Sukma Prabu Karna Mandra menitis ke Raden Suryatmaja, yang kemudian menjadi raja Ngawangga menggantikan Prabu Karna Mandra, bergelar Prabu Karna Basusena. Dengan demikian jelas bahwa aspek raksasa dalam diri Prabu Karna ditunjukkan melalui keberadaan sukma Prabu Karna Mandra dalam dirinya. Pola penitisan seperti ini dijumpai pula dalam beberapa lakon wayang yang lain, di antaranya Prabu Kresna yang menjadi raja Dwarawati karena mengalahkan raja Dwarawati, Prabu Yudakalakresna yang sukmanya menitis ke dalam Narayana (nama Prabu Kresna sebelum menjadi raja). Demikian juga Prabu Puntadéwa, dia mendapat gelar Prabu Yudhistira karena menjadi tempat penitisan Prabu Jim Yudhistira, raja Ngamarta.

Aspek raksasa yang ditunjukkan melalui kapasitasnya sebagai putra Surya dapat dilacak melalui namanya. Dewa Surya adalah dewa matahari, dalam tradisi wayang disebut juga Sang Hyang Radité atau Dité. Apabila kata dité ini dipandang sebagai kata bentukan, maka vokal "e” merupakan vokal sandi yang dibangun dari penggabungan vocal “ $i$ ” dan " $a$ ”, yakni ditia. Ditia, dalam penulisan, pembacaan, dan pelafalannya sering menjadi ditya. Istilah ditya dalam tradisi wayang digunakan sebagai identifikasi raksasa. Aspek raksasa Prabu Karna dalam hubungannya dengan putra Surya dipertegas dengan penggunaan nama Arka. Arka adalah raksasa atau danawa (Hopkins, 1986: 84).

Yoga Prabu Karna sebagai raksasa sakti gagal diakibatkan oleh kesombongannya menolak kehadiran naga Hardawalika. Artinya bahwa Prabu Karna gagal mengendalikan atau mengatasi kundalini sebagai sarana penting untuk melakukan lompatan spiritual menuju alam niskala; sebaliknya Arjuna, karena membunuh Hardawalika, maka dia berhasil mengendalikan kundalini sehingga dapat menyatu dengan Syiwa sebaga isthadewata dalam samadinya sebagaimana Bima membunuh Naga Nabatnawa dalam Lakon Dewa Ruci. Keberhasilan samadi Arjuna di sini ditandai dengan mahkotanya yang hancur oleh panah Prabu Karna. Peristiwa ini merupakan pengulangan keberhasilan samadi Arjuna dalam lakon Ciptahening atau Arjunawiwaha. Hancurnya mahkota merupakan simbol dari hancurnya kesombongan, yang kemudian digantikan dengan mahkota Syiwa. Di sini Arjuna telah mendapatkan pencerahan dan dapat bertemu dengan hakekat sakti (Syiwa) yang sebenarnya (periksa Wiryamartana, 1990: 371), sehingga Arjuna berdiri sebagai manifestasi Syiwapasupati yang ditandai oleh kematian Prabu Karna dengan senjata Pasupati milik Arjuna.

Keberhasilan Arjuna sebagai manusia sakti dalam samadinya (Baratayuda) tidak lepas dari kapasitasnya sebagai ksatria yang memiliki kewajiban memayu hayuning bawana (menjaga keseimbangan alam semesta). Dukungan alam di sini ditunjukkan dengan keberadaan Prabu Salya dan Prabu Kresna. Prabu Salya dan Prabu Kresna yang mengganggu usaha Prabu Karna dalam membunuh Arjuna merupakan upaya alam semesta untuk melalukan siklusnya. Prabu Salya dalam kapasitasnya sebagai bumi merupakan transformasi dunia bawah yang sudah mulai membutuhkan datangnya hujan untuk menyegarkan dirinya demi 
kehidupan semua makhluk yang disangganya, dan Prabu Kresna sebagai manifestasi Sang Hywang Suman dalam tugasnya menjaga keseimbangan alam agar terhindar dari kehancuran; dan tugas tersebut dilaksanakan oleh Arjuna.

Peristiwa dalam Karna Tandhing ini tidak saja secara mikro sebagai keberhasilan samadi Arjuna, tetapi sekaligus secara makro sebagai fenomena ritual. Hal ini ditunjukkan melalui tindakan-tindakan yang dilakukan Prabu Salya dan Prabu Kresna. Prabu Salya sebagai bumi dapat diasosiasikan sebagai tataran bawah (epik), sedangkan Prabu Kresna sebagai penguasa Untarasagara (dunia atas) dapat diasosiasikan sebagai tataran mite. Memang pada dasarnya di sini Prabu Salya berada dalam kapasitasnya sebagai tataran epik karena hanya sebagai sais, sedangkan Prabu Kresna sebagai penjelmaan Wisnu merupakan tataran mite. Satu sisi Prabu Salya sebagai tataran epik (bawah) menuju ke "atas" melalui identifikasi tindakannya melompatkan kuda keretanya ketika Prabu Karna memanah Arjuna; dan di sisi lain, Prabu Kresna sebagai tataran mite (dunia atas) menurunkan keretanya. Kedua tindakan tersebut bertujuan untuk menyelamatkan Arjuna. Artinya bahwa Arjuna merupakan tujuan dari tindakan naik oleh tataran bawah (epik) dan tindakan turun oleh tataran atas (mite). Dengan demikian Arjuna dapat diasosiasikan sebagai tataran ritual.

Lakon Karna Tandhing sebagai sebuah pertunjukan, dan dalang sebagai pelakunya, di sini kapasitas dalang adalah sebagai yogin. Semua yang terjadi dapal pentas merupakan sesaji mantra dan laku sang dalang dalam samadinya. Yadnya Arjuna sekaligus yadnya sang dalang sehingga keberhasilan Arjuna merupakan keberhasilan yoga sang dalang (periksa Wahyudi, 2012: 576-577). Dengan demikian jelas bahwa Lakon Karna Tandhing merupakan ritual pemujaan Syiwa melalui Naga Hardawalika dan Prabu Karna sebagai pasubanda.

\section{Penutup}

Berdasarkan uraian di atas tampak bahwa Lakon Karna Tandhing tidak hanya mempersoalkan tataran mikro, tetapi sekaligus tataran makro. Kedua tataran tersebut berelasi dengan seimbang, dan meskipun saling tumpah-tindih tetapi tidak terjadi benturan pemahaman di dalamnya. Kapasitas Naga
Hardawalika di satu sisi sebagai manivestasi awan, spirit of water; dan di sisi lain sebagai pasubanda dalam yadnya Arjuna, dan bahkan pada sisi berikutnya sebagai manifestasi kundalini, meski demikian kepentingan-kepentingan tersebut tidaklah saling bertolak belakang atau berbenturan, tetapi justru saling mendukung satu dengan yang lainnya. Demikian juga Prabu Karna, di satu sisi sebagai ksatria yang tangguh dan setia pada janjinya, tetapi di sisi lain Prabu Karna sebagai manifestasi Vrrtra sang penguasa kemarau; dan di sisi yang lain lagi berdiri sebagai manifestasi raksasa sakti yang gagal dalam samadinya. Demikian juga yang terjadi pada Prabu Salya, Prabu Kresna, dan Arjuna.

Keberhasilan Arjuna mengalahkan Prabu Karna merupakan manifestasi pergantian musin kemarau ke musim hujan; dan di sisi lain sebagai manivestasi yogin yang berhasil dalam samadinya; bahkan di sisi yang lain lagi, Arjuna sebagai identifikasi kehadiran sang Isthadewata. Di sisi lain lagi bahwa keberhasilan samadi Arjuna merupakan identifikasi keberhasilan samadi sang dalang maupun sang penggubah Lakon Karna Tandhing dalam menghadirkan Syiwa sebagai Isthadewatanya. Semua teori tersebut menjalin sedemikian rapi dalam sebuah jalinan intertekstualitas dalam membangun Lakon Karna Tandhing. Kompleksitas persoalan yang didapat dari uraian di atas merupakan penjabaran tentang kandungan makna Lakon Karna Tandhing mengenai pengetahuan tentang makrokosmos dan mikrokosmos sekaligus. Semua tertata dalam sistem mitis yang berlapislapis membentuk jalinan cerita yang sedemikian dahsyat, yaitu Lakon Karna Tandhing.

\section{Kepustakaan}

\section{a. Acuan}

Bhattacharji, Sukumari.1970. The Indian Theogony; A Comparative Study of Indian Mythology from The Vedas to The Puranas. New York: Cambridge At The University Press.

Hiltebeitel, Alf. 1990. The Ritual of Battle; Krishna in The Mahabharata, State University of New York Press, Albany.

Hopkins, E. Washburn. 1986. Epic Mythology. Delhi, Varanasi, Padna, Madras: Motilal Banarsidass. 
Katz, Ruth Cecily.1989. Arjuna In The Mahabharata; Where Krishna is, There is Victory. Columbia: University of South Carolina Press.

Kuiper, F.B.J. 1979. Varuña And Vidũşaka; On the Origin of the Sanskrit Drama. Amsterdam, Oxford, New York: North-Holland Publishing Company.

Macdonell, A. A. 1974. Vedic Mythology, Delhi, Varanasi, Padna, Madras: Motilal Banarsidass.

Mardiwarsito, L. 1990. Kamus Jawa KunaIndonesia, Ende: Nusa Indah.

Mulyono, Sri. 1992. Tripama Watak Satria dan Sastra Jendra, Jakarta, Haji Masagung.

Padmosoekotjo, S. 1990. Silsilah Wayang Purwa mawa Carita; Jilid IV, PT Citra Jaya Murti, Surabaya.

Wahyudi, Aris. 2012. Lakon Dewa Ruci: Cara Menjadi Jawa; sebuah analisis strukturalisme Lévi-Strauss, Yogyakarta: Bagaskara. 2009. "Lakon Wahyu Widayat:
Aspek Rajawi Indra Sebagai Legitimator Kekuasaan Raja Jawa” dalam Panggung, Jurnal Ilmiah Seni dan Budaya, Vol. 19, No.1, Januari-Maret 2009.

Widyatmanta, Siman. 1968. Adiparwa; Jilid II, Jogjakarta: U.D. "Spring”.

Wiryamartana, I Kuntara. 1990. Arjunawiwaha: Transformasi Teks Jawa Kuna Lewat Tanggapan dan Penciptaan di Lingkungan Sastra Jawa, Yogyakarta: Duta Wacana University Press.

\section{b. Audio-Visual}

Hadi Sugito, Ki. t.t. Alap-alapan Surtikanti. Koleksi pribadi.

Mudjaka Djaka Rahardja, Ki. 1990. Lakon Kresna Duta, rekaman pita kaset atas pertunjukan Langsung di Gombang Boyolali. Koleksi pribadi.

Nartosabdo, Ki. t.t. Lakon Kresna Duta. Kaset. Lokananta Record. 